\title{
T-Cell Lymphoma in a Patient with Neurofibromatosis Type 1 and AIDS
}

\author{
Izana Junqueira de Castro ${ }^{a} \quad$ Esther Botelho Soares da Silva $^{a}$ \\ Talita Rezende dos Santos ${ }^{a} \quad$ Amanda Barroso de Freitas $^{a}$ \\ Inara Junqueira de Castro ${ }^{b}$ Alessandra Santos Portela $^{a}$ \\ Marilza Campos de Magalhães ${ }^{a}$ Karina Lebeis Pires ${ }^{a}$ \\ Guilherme Almeida Rosa da Silva ${ }^{a}$ \\ Marcelo Costa Velho Mendes de Azevedo ${ }^{a}$ \\ aUniversidade Federal do Estado do Rio de Janeiro (UNIRIO), Rio de Janeiro, Brazil; \\ bUnião das Faculdades dos Grandes Lagos (UNILAGO), São José do Rio Preto, Brazil
}

\section{Keywords}

HIV · AIDS · Neurofibromatosis type $1 \cdot$ T-cell lymphoma

\begin{abstract}
Neurofibromatosis type 1 (NF1) and AIDS are risk factors for the development of malignant neoplasms, including hematological malignancies, such as non-Hodgkin lymphoma. NF1 is an autosomal dominant disease that primarily manifests as café-au-lait spots, dermal neurofibromas, axillary and/or inguinal ephelides or freckles, plexiform neurofibromas, Lisch nodules, and bone deformities. In this report, we present a 38-year-old female patient with NF1 from childhood and AIDS who developed peripheral T-cell lymphoma with good response to chemotherapeutic treatment.

(C) 2017 The Author(s)

Published by S. Karger AG, Basel
\end{abstract}




\section{Case Reports in Oncology}

\section{Introduction}

Neurofibromatosis (NF) is a denomination comprising 3 diseases, NF type 1 (NF1), NF type 2, and schwannomatosis, all of which are diseases of autosomal dominant genetic origins. NF1 is the most common disease, with an incidence of 1/3,000 live births [1], and it has also been referred to as peripheral or classical NF [2], while NF2 and schwannomatosis affect approximately $1 / 25,000$ live births [3]. NF is the most common phakomatosis, which includes congenital developmental malformations that simultaneously affect the skin, retina, and nervous system, such as Sturge-Weber syndrome, tuberous sclerosis, and Von HippelLindau syndrome. NF1 accounts for $90 \%$ of all cases and is one of the most common autosomal dominant diseases in humans [4]. One of the main characteristics of this disease is its systemic and progressive involvement, which presents impairment of neurological functions and physical deformities. NF1 primarily manifests as café-au-lait spots, dermal neurofibromas, axillary and/or inguinal ephelides or freckles, plexiform neurofibromas, Lisch nodules, and bone deformities [2].

NF1 commonly occurs in 1 or 2 generations, but in some families it can occur in 4-6 generations. The term "expressiveness" refers to the variability of physical or clinical signs associated with a given gene. NF1 is one of the genetic diseases that best exemplifies this phenomenon, as there is ample clinical variability, even intrafamilial variability. In addition, a severely affected patient may produce offspring with a milder clinical picture and vice versa [5].

Currently, the National Institutes of Health $(\mathrm{NIH})$ criteria for the diagnosis of NF1 include 2 or more of the following criteria: 6 or more café-au-lait spots $>5 \mathrm{~mm}$ in diameter in prepubertal patients or $>15 \mathrm{~mm}$ in diameter in postpubertal patients; 2 or more neurofibromas of any type or a plexiform neurofibroma; freckles in an axillary or inguinal area; glioma of the optic nerve; 2 or more Lisch nodules; a distinctive bone lesion, such as sphenoid wing dysplasia or thinning of the bone cortex with or without pseudoarthrosis; and a first-degree relative (parents, siblings, or children) with NF1 based on the above criteria [6].

The 5 subtypes of neurofibromas are cutaneous, subcutaneous, nodular, plexiform, and diffuse [7]. Other associated findings include visual disturbances, cognitive disorders, growth problems, and musculoskeletal disorders [7]. The diagnosis is primarily made through clinical criteria and the observation of changes on a chest X-ray [2, 8].

Mutation of the gene encoding neurofibromin is the main factor contributing to the development of NF1. The NF1 gene was cloned and mapped to human chromosome 17q11.2 $[9,10]$. The functions of neurofibromin are not fully understood, and this protein can act as a tumor suppressor [11].

Patients with NF1 have an increased risk of malignancies estimated to be at 5-15\% [12]. Thus, only a small number of malignant tumors, which typically appear before 38 years of age from an old neurofibroma, have been reported as complications of this disease [11,12]. These malignancies are an important cause of morbidity and mortality in NF1 [6].

NF1 is associated with the development of malignancies, including those of neural crest origin, such as pheochromocytoma, neuroblastoma, and melanoma. Among the tumors that do not originate in the neural crest are Wilms tumor, rhabdomyosarcoma, malignant nodular hidradenoma, and leukemia. Malignant peripheral nerve sheath tumors are associated with NF1 and are a potential cause of mortality in adult patients with NF1 [6]. Few reports 
concern the development of malignant lymphomas in patients with NF1 [13], and the mechanism of the association between neurofibromatosis and malignant lymphomas has not yet been elucidated [14]. Malignant lymphoma is defined as a solid tumor of the immune system, and there are 2 types of lymphomas: Hodgkin lymphoma and non-Hodgkin lymphoma (NHL) [14].

NHLs are a heterogeneous group of lymphoproliferative diseases typically affecting nodal and extranodal sites and producing a plethora of nonspecific clinical features [4]. There are several classifications of NHL. To identify the type of NHL, it is necessary to collect a sample of tissue for later laboratory and microscopic analyses. Most cases of NHL affect B lymphocytes [4].

AIDS-related NHL is typically a late event in the course of HIV infection and is associated with a low CD4+ T-cell count and a high viral load. The most common AIDS-related NHLs are B-cell lymphomas, aggressive and generally high-degree malignancies, such as large cell and Burkitt lymphomas [4].

The objective of the present study is to report a case of the association of NF1 and AIDS in a female patient who developed a T-cell NHL as well as to discuss the literature concerning this association.

\section{Case Report}

The patient was a 38-year-old , black, single female from the state of Rio de Janeiro, who was HIV positive (diagnosed in August 2014, presenting with pneumonia and herpes zoster), with irregular use of antiretroviral therapy - tenofovir $300 \mathrm{mg}$ + lamivudine $300 \mathrm{mg}+$ efavirenz $600 \mathrm{mg}$. At the time of admission, the HIV viral load was recorded at 2,558 copies per $\mathrm{mL}$, with TCD4+ lymphocyte counts at 170 cells $/ \mathrm{mm}^{3}$ and TCD8+ lymphocytes at 1,478 cells $/ \mathrm{mm}^{3}$. The patient had been diagnosed as a carrier of NF1 during childhood. At the time of hospitalization, the patient had axillary ephelides (Fig. 1), café-au-lait spots, and neurofibromas in the frontal trunk (Fig. 2), upper limbs, and lower limbs. Her family members (mother and sister) also presented with neurofibromas.

In June 2014, she noticed a mobile, fibroelastic mass of approximately $1 \mathrm{~cm}$ in the right inguinal region accompanied by hyperemia, flushing, edema, and local pain of high intensity, pulsatile, without mitigating or aggravating factors. She also had nocturnal sweating, dry cough, and unmeasured and unmedicated fever. The symptoms evolved, with worsening of the pain and a progressive increase of the mass, with fistulization of liquid and whitish secretion with traces of blood. She also reported a weight loss of $13 \mathrm{~kg}$ in 5 months. The patient denied dyspnea, gastrointestinal tract abnormalities, inappetence, and insomnia.

At the time of admission, there were palpable posterior cervical lymph nodes, palpable left popliteal lymph nodes without phlogistic signs, and palpable liver with $20 \mathrm{~cm}$ hepatimetry. The hemogram showed pancytopenia, and the patient underwent a platelet transfusion. Computed tomography of the chest revealed bronchiectasis and the absence of a mediastinal mass. A biopsy of the inguinal mass was performed, and the histopathological examination revealed a peripheral CD8+ T-cell lymphoma (Fig. 3) and HTLV-1 serology, with a nonreactive result. 
After diagnosis, the patient was staged as stage III according to Ann Arbor Staging. She received treatment with a CHOEP (cyclophosphamide, doxorubicin, vincristine, etoposide and prednisone) chemotherapy cycle during hospitalization, presenting a satisfactory evolution with a reduction of lymph node size in the posterior cervical, left popliteal, and right inguinal regions. Outpatient follow-up was conducted at the Immunology and Hematology Department to complete 5 more CHOEP cycles, clinical evaluation, and antiretroviral treatment follow-up.

In 2 years, there was no recurrence of lymphoma. We also observed a weight gain of 21 $\mathrm{kg}$, undetected viral load and the CD4+ T-lymphocyte count increased to $231 \mathrm{copies} / \mathrm{mm}^{3}$.

\section{Discussion}

Lymphomas in patients with NF1 have rarely been reported, although a populationbased study in the UK concludes that these patients are 3.3 times more likely to present diffuse NHL than patients without NF1 [15]. A PubMed search was performed with the keywords "neurofibromatosis type 1" and "lymphoma," and T-cell lymphoma was the immunophenotype most frequently reported in patients with NF1 (Table 1).

The peripheral T-cell lymphoma presented in this study presents a heterogeneous morphological group of aggressive neoplasias that share a mature T-cell immunophenotype associated with a bleak prognosis and low response to CHOP chemotherapy treatment [4]. However, in this case, the patient's response to the scheme was satisfactory.

Subsequently, the keywords "neurofibromatosis type 1," "lymphoma," and "AIDS" were inserted, and this case was the first describing T-cell lymphoma in a patient with NF1 and AIDS.

AIDS is characterized by severe immunosuppression, leading to the occurrence of cachexia, opportunistic infections, and neoplasias. AIDS-defining neoplastic diseases include Kaposi sarcoma, NHL, and invasive carcinoma of the cervix [4].

The B-cell phenotype is the most common lymphoma in AIDS, and grade III or IV immunoblastic lymphoma, Burkitt lymphoma, and primary central nervous system lymphoma are the 3 major types of lymphoma associated with AIDS. Lymphomas are a late manifestation of HIV infection that typically occur in patients with few CD4+ T cells $\left(<200\right.$ cells $\left./ \mathrm{mm}^{3}\right)$ [4]. As the disease progresses, the risk of developing lymphomas increases [4]. In this case, the patient's TCD4+ cell count of 170 cells $/ \mathrm{mm}^{3}$ was expected for the manifestation of lymphoma in the course of AIDS.

The clinical picture of NHL is primarily characterized by lymph node enlargement, nocturnal sweating, fever, and weight loss, of which the latter 3 characteristics are known as B symptoms [4]. The patient in this case had a clinical presentation compatible with the description in the literature, and lymph node tuberculosis, cat scratch disease, deep mycoses, and suppurative lymphadenitis were differential diagnoses.

Thus, we conclude that the clinical course of this case is remarkable in 2 important aspects: (1) the peripheral T-cell NHL phenotype, which is of rare prevalence in patients with AIDS; and (2) the fact that the patient presented 2 risk factors for the manifestation of malignancies and the questioning of which of these conditions contributed most to this manifestation or whether the risk factors contributed equally to the appearance of NHL. 
In addition, the variety of malignant tumors, including lymphomas, should be considered in patients with NF1, as T-cell lymphoma may not be a rare complication in such patients, and NF1 may be a risk for the development of this type of malignancy.

\section{Statement of Ethics}

The patient in this study gave informed consent and the study protocol was approved by the Ethics Committee of the Hospital Universitário Gaffrée e Guinle.

\section{Disclosure Statement}

The authors have no conflicts of interest to disclose with any of the material presented within the manuscript.

\section{References}

1 Friedman JM: Epidemiology of neurofibromatosis type 1. Am J Med Genet 1999;89:1-6.

2 Muniz MP, Ferraz Filho JRL, Souza AS, Zanusso SH, Pavarino-Bertelli EC, Goloni-Bertollo EM: Neurofibromatose tipo 1: aspectos clínicos e radiológicos. Rev Imagem 2006;28:87-96.

-3 Ferner RE, Huson SN, Thomas N, Moss C, Willshaw H, Evans DG, et al: Guideline for the diagnosis and management of individuals with neurofibromatosis 1. J Med Genet 2007;44:81-88.

4 Longo DL, Kasper DL, Jameson JL, Fauci AS, Hauser SL, Loscalzo J: Harrison. Princípios de Medicina Interna, ed 18. McGraw-Hill-Artmed.

5 Darrigo Jr LG, Bonalumi Filho A, D’Alessandro DSM, Geller M: Neurofibromatosis type 1 in childhood: review of clinical aspects. Rev Paul Pediatr 2008;26:176-182. Courtney RH, McBurney EI: Cutaneous T-cell lymphoma in a patient with neurofibromatosis type 1. Cutis 2003;72:27-30.

7 Eichenfield LF, Levy ML, Paller AS, et al: Guidelines of care for neurofibromatosis type 1. J Am Acad Dermatol 1997;37:625-630.

8 Beiro AC, Dantas JFC, Conte Neto N, Nasciben MB, Scarso Filho J: Neurofibromatose: uma desordem hereditária: relato de caso de ocorrência em mãe e filha. R Ci Md Biol 2008;7:193-197.

-9 Cawthon RM, Weiss R, Xu G, Viskochil D, Culver M, Stevens J, Robertson M, Dunn D, Gesteland R, O'Connell P, White R: A major segment of the neurofibromatosis type 1 gene: cDNA sequence, genomic structure, and point mutations. Cell 1990;62:193-201.

10 Li Y, O'Connell P, Breidenbach HH, Cawthon R, Stevens J, Xu G, Neil S, Robertson M, White R, Viskochil D: Genomic organization of the neurofibromatosis 1 gene (NF1). Genomics 1995;25:9-18.

11 Kim SJ, Seo JH, Lee SW, Han E, Lee ES, Cha SH, Seo BK: A case of non-Hodgkin's lymphoma in a patient with neurofibromatosis type 1. Korean J Intern Med 2003;18:202-205.

12 Lueangarun S, Auewarakul CU: Diffuse large B cell lymphoma presenting as Horner's syndrome in a patient diagnosed with neurofibromatosis type 1: a case report and review of the literature. J Med Case Rep 2012;6:8.

13 Uyttebroeck A, Legius E, Brock P, Van de Cassey W, Casaer P, Casteels-Van Daele M: Consecutive glioblastoma and B cell non-Hodgkin's lymphoma in a young child with von Recklinghausen's neurofibromatosis. Med Pediatr Oncol 1995;24:46-49.

14 Dohi O, Hatori M, Ichinohasama R, Hosaka M, Hashimoto S, Kokubun S: Diffuse large B-cell lymphoma arising in a patient with neurofibromatosis type I and in a patient with neurofibromatosis type II. Tohoku J Exp Med 2006;208:169-176. 


\section{Case Reports in Oncology}

15 Oki M, Nanao T, Shinoda T, Tsuda A, Yasuda A, Seki T, Ozawa H, Nakamura N, Takagi A: Primary effusion lymphoma-like lymphoma in a patient with neurofibromatosis type 1. Tokai J Exp Clin Med 2016;41:123-129.

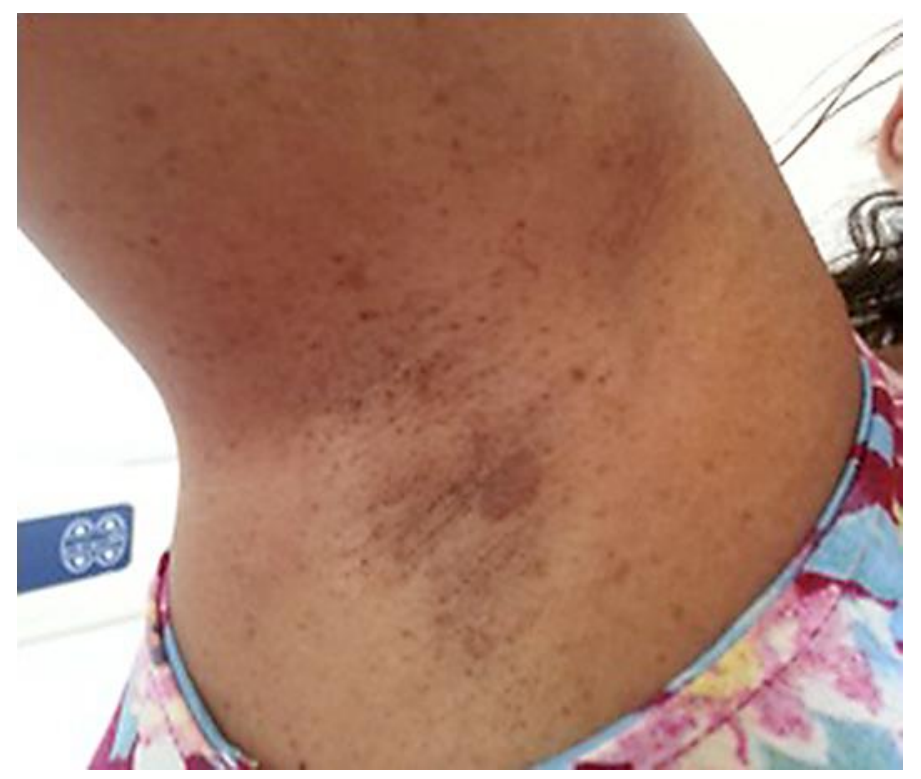

Fig. 1. Ephelides and café-au-lait spots in the axillary region. 


\section{Case Reports in Oncology}

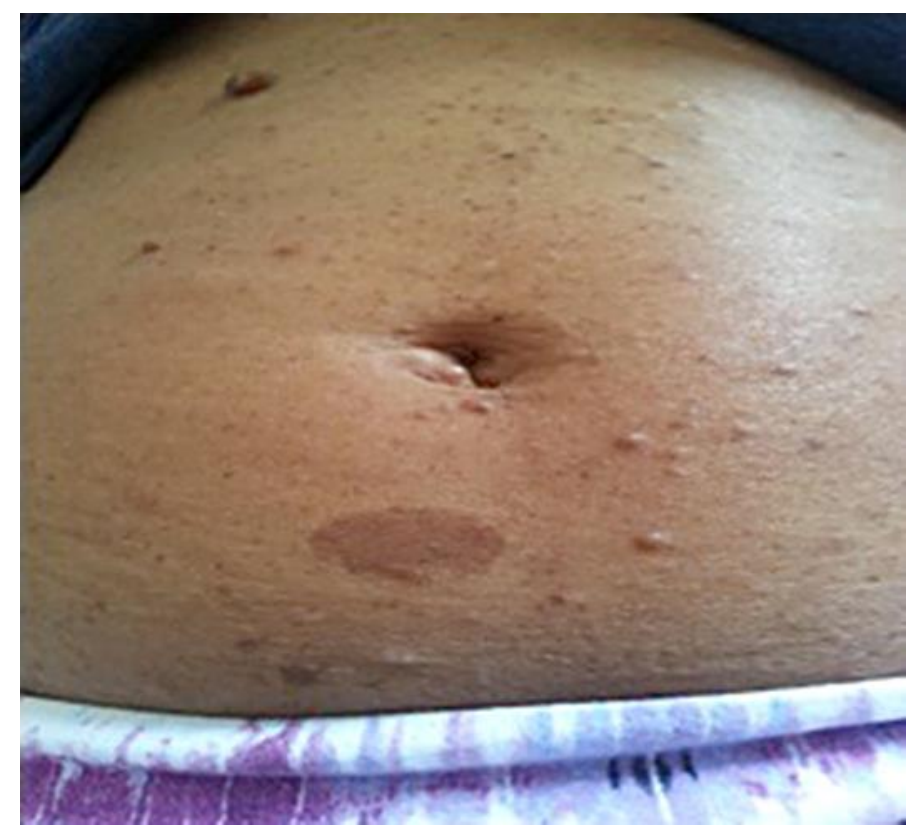

Fig. 2. Café-au-lait spots and neurofibromas in the umbilical region.

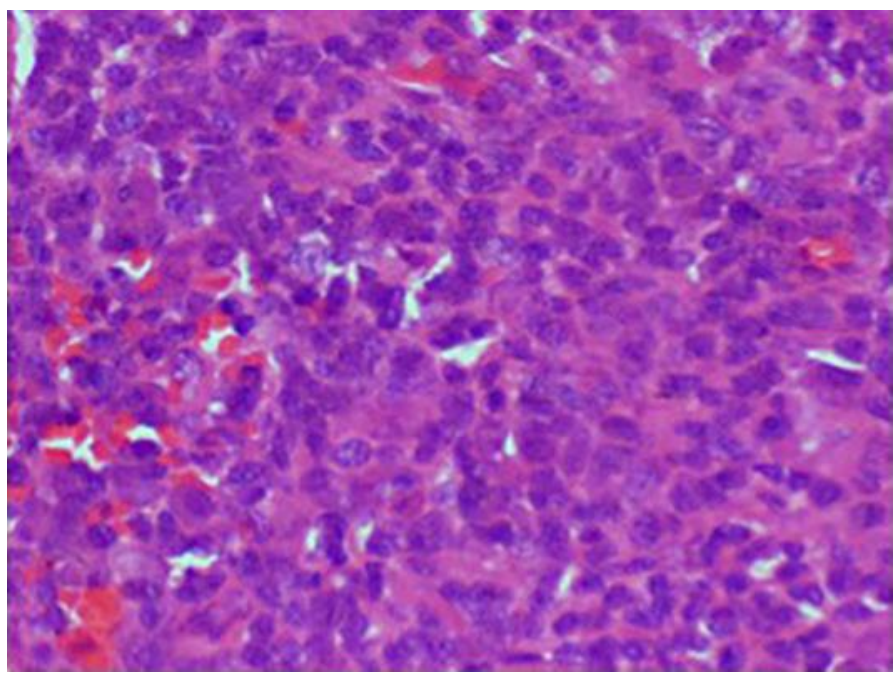

Fig. 3. Histopathological evidence of peripheral CD8+ T-cell lymphoma. 
Table 1. Lymphoma case reports in patients with NF1

\begin{tabular}{|c|c|c|c|c|c|}
\hline Authors & Cases, $n$ & Age, years & Gender & Lymphoma & Outcome \\
\hline Oki et al. & 1 & 73 & $\mathrm{~F}$ & PEL like & Cure \\
\hline Varan et al. & 1 & 4 & M & Lymphoblastic T cells & Death \\
\hline Reich et al. & 1 & 28 & $\mathrm{~F}$ & T cells & Cure \\
\hline Chudy-Onwugaje et al. & 1 & 59 & M & Large B cells & Cure \\
\hline de Blank et al. & 1 & 6 & M & $\begin{array}{l}\text { HL with nodular lymphocytic } \\
\text { predominance }\end{array}$ & Cure \\
\hline Incecik et al. & 2 & $8 / 7$ & $\mathrm{M} / \mathrm{F}$ & HL/NHL T cells & 2 cures \\
\hline Soda et al. & 1 & 70 & M & Large B cells & Cure \\
\hline Cheuk et al. & 1 & 21 & M & Anaplastic large cells & Death \\
\hline Eoli et al. & 1 & 60 & $\mathrm{~F}$ & B cells & Death \\
\hline Lueangarun et al. & 1 & 28 & M & Large B cells & Cure \\
\hline Jaremko et al. & 1 & - & - & HL & - \\
\hline Dang et al. & 1 & - & - & HL & - \\
\hline Rampisela et al. & 1 & 14 & M & Lymphoplasmocytic and Burkitt & - \\
\hline Cajaiba et al. & 1 & 6 & $\mathrm{~F}$ & Lymphoblastic T-cells & - \\
\hline Dohi et al. & 1 & 50 & $\mathrm{~F}$ & Large B cells & - \\
\hline Matsuzaki et al. & 1 & 59 & M & B cells & Death \\
\hline Wertelecki et al. & 1 & 16 & M & Undifferentiated & Death \\
\hline Berman et al. & 1 & 20 & $\mathrm{~F}$ & Burkitt & Cure \\
\hline Zein et al. & 1 & 47 & M & Large B cells & - \\
\hline Kim et al. & 1 & 77 & $\mathrm{~F}$ & Large B cells & Cure \\
\hline Herbert et al. & 1 & - & - & Cutaneous T cells & - \\
\hline Braam et al. & 1 & - & - & Cutaneous T cells & - \\
\hline Itoh et al. & 1 & 65 & M & T cells & Death \\
\hline Uyttebroeck et al. & 1 & 4 & $\mathrm{~F}$ & B cells & Cure \\
\hline Stiller et al. & 5 & $7 / 4 / 1 / 13 / 7$ & $4 \mathrm{M} / 1 \mathrm{~F}$ & $3 \mathrm{~T}$ cells/centroblastic/B cells & $\begin{array}{l}3 \text { deaths and } 2 \\
\text { cures }\end{array}$ \\
\hline Shearer et al. & 1 & 17 & M & Immunoblastic & - \\
\hline Agaimy et al. & 1 & 51 & $\mathrm{~F}$ & Anaplastic large cells & Death \\
\hline Tsvetkova et al. & 1 & - & - & HL & - \\
\hline Schiff et al. & 1 & 21 & $\mathrm{~F}$ & Burkitt & Cure \\
\hline Barbaric et al. & 5 & $2 / 10 / 15 / 7 / 14$ & $5 \mathrm{M}$ & $\begin{array}{l}2 \mathrm{~T} \text { cells/B cells/lymphoblastic/ } \\
\text { large cells }\end{array}$ & $\begin{array}{l}1 \text { death and } 4 \\
\text { cures }\end{array}$ \\
\hline Trattner et al. & 1 & 9 & $\mathrm{~F}$ & T cells & Cure \\
\hline Kremen et al. & 1 & - & - & Lymphocytic & - \\
\hline Kaplan et al. & 2 & $1 / 2$ & $2 \mathrm{~F}$ & 2 lymphoblastic & 2 deaths \\
\hline Astigarraga Aguirre et al. & 1 & - & $\mathrm{F}$ & NHL & - \\
\hline
\end{tabular}

-, absent data, not specified or not accessible; PEL, primary effusion lymphoma; HL, Hodgkin lymphoma; NHL, non-Hodgkin lymphoma. 